\title{
CONSTRUINDO UM DATA CENTER
}

WAGNER LUIZ ZUCCHI

ANDERSON BARRETO AMÂNCIO 


\section{RESUMO}

A construção de um moderno centro de processamento de dados exige um correto balanço entre tendências tecnológicas, eficiência, fatores ambientais e baixo custo. Neste artigo os autores tentam apresentar os cuidados no projeto desse tipo de ambiente de forma acessível ao público não especializado.

Palavras-chave: data center, projeto de datacenter, projeto modular, infraestrutura para data center.

\section{ABSTRACT}

Building a modern center for processing data requires striking the right balance between technology trends, efficiency, environmental factors and low cost. In this article the authors seek to present the issues to consider when designing a project of this type of environment in a way that is accessible to a non-expert audience.

Keywords: data center, data center project, modular project, data center infrastructure. 


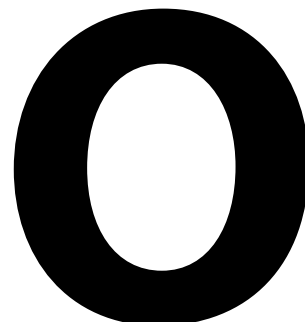

termo data center, que pode ser traduzido como "centro de dados", aparece com frequência crescente na literatura especializada ou não. A importância das informações armazenadas nos seus equipamentos e a quantidade de dinheiro que se gasta na construção de um data center explicam que eles sejam notícia na grande imprensa e chamem a atenção do público, quase como novos templos da moderna civilização.

É justificável, portanto, que o não especialista se pergunte: o que exatamente é um data center? Quais suas principais funções? Como ele deve ser projetado e construído? Por que são tão caros? Que considerações devem ser feitas para a preservação dos investimentos realizados? Quais são seus impactos ambientais? Qual a importância da cloud computing (computação em nuvem) para um data center moderno? Neste artigo dois professores do curso de projeto de data centers do programa de Educação Continuada da Escola Politécnica tentam responder a essas perguntas para o público em geral, sem os detalhes de um curso para engenheiros.

Um data center é o sucessor dos centros de processamento de dados dos anos 70 e 80. Uma diferença importante é que em um data center pode-se ter centenas ou milhares de computadores, ao invés de um único, ou alguns poucos computadores, em um CPD. A segunda diferença é consequência do avanço tecnológico da informática: a capacidade de processamento e de armazenagem de um centro moderno é muito maior que a do ambiente legado. Uma terceira diferença ainda deve ser apontada: um CPD clássico é essencialmente um produto, adquirido de um único fornecedor, que atua como projetista, integrador e implementador de todo o ambiente. Em um moderno data center a convivência de equipamentos de dezenas de fornecedores é quase sempre inevitável.

A Figura 1 tenta ilustrar visualmente a diferença entre um CPD clássico e um data center moderno.

A consideração dessas diferenças, ou melhor, dessas características de um moderno data center, faz surdirem algumas questões de modo quase inevitável.

Antes de tudo, um data center precisa ser bem planejado, ou melhor, precisa ser projetado. $\mathrm{O}$ aumento da quantidade de computadores faz aumentar o número de conexões de forma geométrica. As pessoas se surpreenderiam se soubessem a frequência com que se encontram situações semelhantes à da Figura 2.

É claro que ninguém inauguraria um data center na situação mostrada nessa fi-
WAGNER LUIZ

ZUCCHI é professor do Departamento de Sistemas Eletrônicos da Escola Politécnica da USP e coordenador do curso Data Centers na Era da Sustentabilidade do Programa de Educação Continuada (Pece) da Escola Politécnica da USP.

ANDERSON BARRETO AMÂNCIO é professor do curso Data Centers na Era da Sustentabilidade do Programa de Educação Continuada (Pece) da Escola Politécnica da USP. 


\section{UM CPD CLÁSSICO (À ESQUERDA) E UM MODERNO DATA CENTER (À DIREITA)}
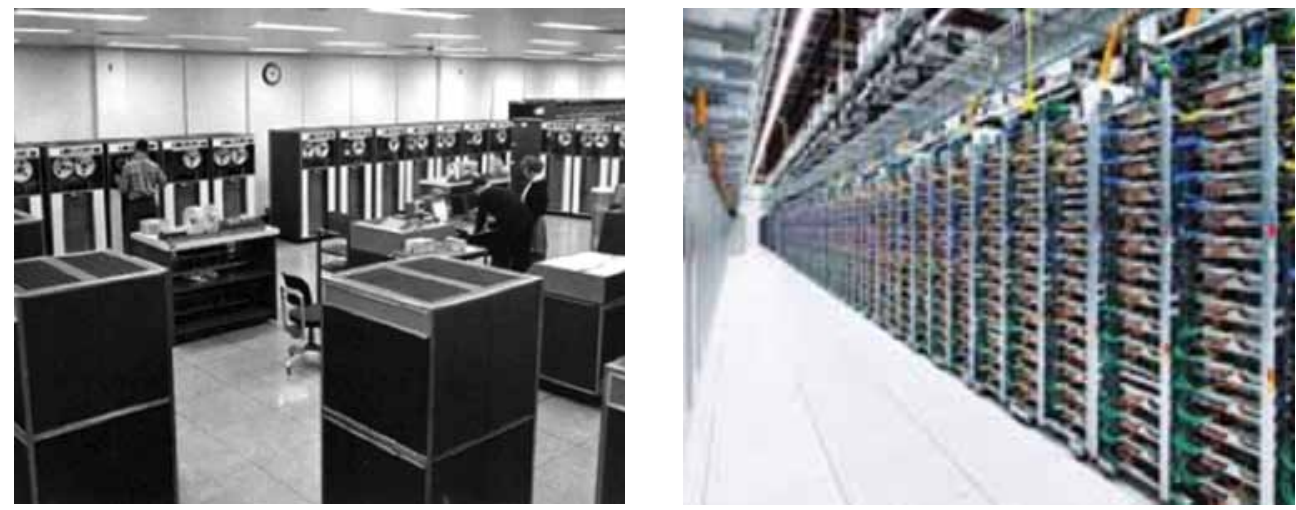

gura. O problema é que o ambiente é mais dinâmico do que se imagina à primeira vista: equipamentos vão se tornando obsoletos e retirados; novos equipamentos, que demandam novas interfaces e novos tipos de ligações, são introduzidos; novos clientes e novas configurações surgem a cada dia. A desordem sempre aumenta, já diz a segunda lei da termodinâmica.

Há alguns anos a máxima taxa de transmissão utilizada na interconexão de computadores de pequeno porte era de $100 \mathrm{Mb} / \mathrm{s}$. Hoje são utilizadas taxas de $10 \mathrm{~Gb} / \mathrm{s}$ em cabos de cobre e de $100 \mathrm{~Gb} / \mathrm{s}$ em fibra óptica. Provavelmente em dois anos, as taxas de transmissão estarão atingindo $1 \mathrm{~Tb} / \mathrm{s}$. Essa evolução trouxe naturalmente uma mudança nos tipos de cabos, no formato dos conectores e nas distâncias envolvidas.

Sem um planejamento adequado, as conexões dos novos equipamentos começam a ser feitas ad hoc, sem seguir os padrões do ambiente. Uma linda locução latina, adequadamente traduzida como "gambiarra".

Mas como planejar um ambiente tão complexo quanto um data center? A melhor resposta nos parece estar no equilíbrio de três fatores: conhecimento das tendências tecnológicas, padronização e modularidade.

É lugar-comum dizer que a tecnologia de TI progride rapidamente. Uma conhecida anedota diz que, se os automóveis tivessem progredido na mesma velocidade dos computadores, hoje, poderiam fazer quinhentos quilômetros com um litro de gasolina. Por outro lado, ocasionalmente o carro pararia sem maiores explicações e só funcionaria novamente depois que todos os passageiros saíssem, entrassem e o ligassem novamente.

O que é pouco dito, e geralmente mal compreendido, é que a tecnologia de TI pro-

\section{FIGURA 2}

\section{PROBLEMAS COM O CABEAMENTO}
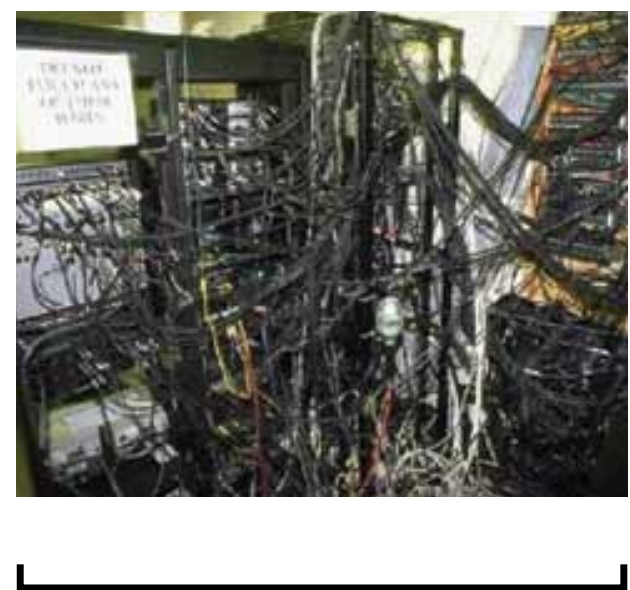
gride com diferentes velocidades em diferentes áreas e que se esse progresso muitas vezes ocorre em diferentes direções. A capacidade de processamento aumenta mais depressa que a capacidade de armazenamento, e na rabeira fica a taxa de transmissão nas redes.

$\mathrm{O}$ aumento da capacidade de processamento geralmente implica maior número de processadores no mesmo espaço físico, ou seja, no aumento da densidade de processadores. O aumento da capacidade de armazenagem também redunda no aumento da densidade espacial de bits. Mas o aumento da taxa de transmissão raramente se faz com a diminuição do tamanho dos cabos usados para a transmissão dos sinais.

Em geral é o contrário que se vê: maiores taxas de transmissão exigem cabos mais grossos ou maior número de cabos. Muitos novos padrões de $100 \mathrm{~Gb} / \mathrm{s}$ usam dez fibras ópticas paralelas para a transmissão dos sinais.

Isso significa que um data center que não se queira tornar precocemente obsoleto deve estar preparado para aumentos de carga de refrigeração, de demandas de alimentação elétrica e de espaço físico para passagem dos cabos.

O dimensionamento desses e de outros recursos é sempre difícil, mas é melhor saber em qual direção as mudanças irão ocorrer para dimensionar as eventuais folgas em cada sistema.

Exatamente aqui entra o segundo conceito importante no projeto de um data center: a modularidade. Não adianta ter folgas de potência elétrica se essa energia não está disponível onde é necessária. Não adianta ter folgas para a passagem dos cabos em muitos pontos e um gargalo na entrada de um centro de distribuição.

A principal vantagem de uma abordagem modular é permitir um balanço mais fácil entre capacidade de equipamentos e capacidade de infraestrutura. Em geral, mas não sempre, são os equipamentos que determinam a infraestrutura.

A abordagem modular no projeto de um data center consiste em determinar um módulo de equipamentos adequado para o ser- viço a ser prestado. Trata-se de uma capacidade apenas bastante grande para satisfazer as demandas de um número significativo de clientes, mas não tão pequena que torne o projeto economicamente inviável.

Em cada módulo devem ser previstas as folgas de energia elétrica, de refrigeração e espaço físico decorrentes das tendências tecnológicas anteriormente descritas. Os módulos de equipamentos vão sendo agrupados, de forma hierárquica, em módulos de infraestrutura que automaticamente incorporam as folgas de proteção tecnológica.

Um exemplo deve ilustrar melhor essa ideia de hierarquia. Suponha que um módulo de processamento é formado por três computadores. Conhecendo o tipo de computadores a ser utilizado, é possível obter as demandas de energia e de refrigeração para esse módulo, bem como as necessidades de espaços para interligações.

Tais computadores provavelmente estarão dentro de um rack, que pode conter três ou quatro módulos de processamento. O rack fará parte de um setor: oito ou doze racks lado a lado. Dois ou três setores formarão um corredor, e o data center será formado pela justaposição de vários corredores.

A partir das demandas de um módulo de equipamento,é possível conhecer como cada componente de hierarquia se comporta e aumentar o ambiente gradualmente de acordo com as necessidades.

Assim, se um rack é acrescentado ao ambiente, sabe-se que, por um lado, três ou quatro módulos de processamento poderão ser acrescentados e, por outro, as novas demandas de infraestrutura poderão ser atendidas dentro do espaço físico disponível.

Existem vários métodos para a determinação de módulos de processamento adequados. O método RLU (rack location unit) é um dos mais conhecidos e consiste em dimensionar os serviços de infraestrutura em cada local de rack. A capacidade funcional de um módulo corresponde a quantidades de memória, quantidades de espaço em disco, número de instruções por segundo, taxa de operações de banco de dados e outras. Em 


\section{ELEMENTOS DE UM MÓDULO NA METODOLOGIA RLU}

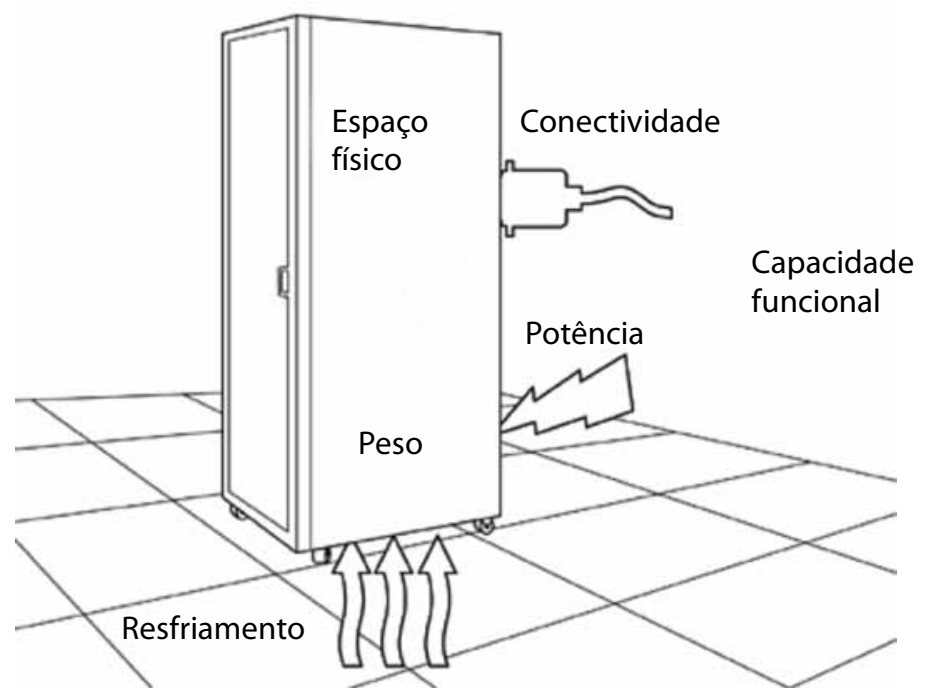

um mesmo ambiente, é possível ter vários tipos de RLUs.

A partir da definição do módulo de equipamentos, são dimensionados os elementos de infraestrutura, que são representados na Figura 3. Esses elementos devem ser recalculados em cada nível da hierarquia de agrupamento, pois sempre há equipamentos extras a serem acrescentados, novas conexões, e assim por diante.

É claro que, se as demandas forem sempre crescentes, um dia a capacidade de alocação de novos módulos, em qualquer uma das hierarquias do data center, estará esgotada. Espera-se que isso possa ocorrer em um prazo semelhante ao da própria obsolescência dos equipamentos.

Pode-se perguntar se essa abordagem de modularidade é aplicável a data centers de diferentes tamanhos, com requisitos bem diferentes de confiabilidade e de tempos de parada. Aqui, entra o terceiro elemento importante do projeto: a normalização.

A principal referência técnica disponível no momento para o projeto de um data center é a norma EIA/TIA-942 (Telecom- munications Infrastructure Standard for Data Centers). Esse padrão prevê vários níveis de confiabilidade em data centers, classificando-os de acordo com o tempo em que o ambiente possa estar inoperante. A Tabela 1 mostra as características funcionais de cada categoria de ambiente.

A abordagem usada nessa norma consiste em definir uma série de elementos funcionais que se conectam hierarquicamente. Os data centers de menor porte e de menor confiabilidade possuem um subconjunto menor de elementos funcionais, mas os padrões de construção permanecem sempre os mesmos.

Assim, qualquer que seja o tamanho do data center sempre teremos elementos como uma área de distribuição horizontal e uma área de distribuição principal. À medida que o número de módulos de equipamentos se amplia, outros desses centros de distribuição podem ser agregados ao ambiente, mantendo a estrutura modular, que é a base do projeto.

A Figura 4, baseada em um modelo da norma citada, mostra os elementos funcionais em um típico data center de nível 1. Como mostra essa figura, um data center 


\section{TABELA 1}

\section{NÍVEIS DE DATA CENTER DE ACORDO COM A EIA/TIA-942}

\begin{tabular}{|c|c|c|c|c|}
\hline & Disponibilidade & Downtime & $\begin{array}{l}\text { Redundância, alimentação } \\
\text { e resfriamento }\end{array}$ & Implementação \\
\hline Tier 1 & $99,671 \%$ & 28,8 horas & Não possui & 3 meses \\
\hline Tier 2 & $99,741 \%$ & 22 horas & $\begin{array}{l}\text { Caminho único com } \\
\text { componentes redundantes }\end{array}$ & 3 a 6 meses \\
\hline Tier 3 & $99,982 \%$ & 1,6 hora & $\begin{array}{l}\text { Múltiplos caminhos, } \\
\text { mas só um ativo }\end{array}$ & 15 a 20 meses \\
\hline Tier 4 & $99,995 \%$ & 0,4 hora & Múlitplos caminhos ativos & 15 a 20 meses \\
\hline
\end{tabular}

\section{FIGURA 4}

\section{ELEMENTOS FUNCIONAIS DE UM DATA CENTER DE ACORDO COM A EIA/TIA-942}

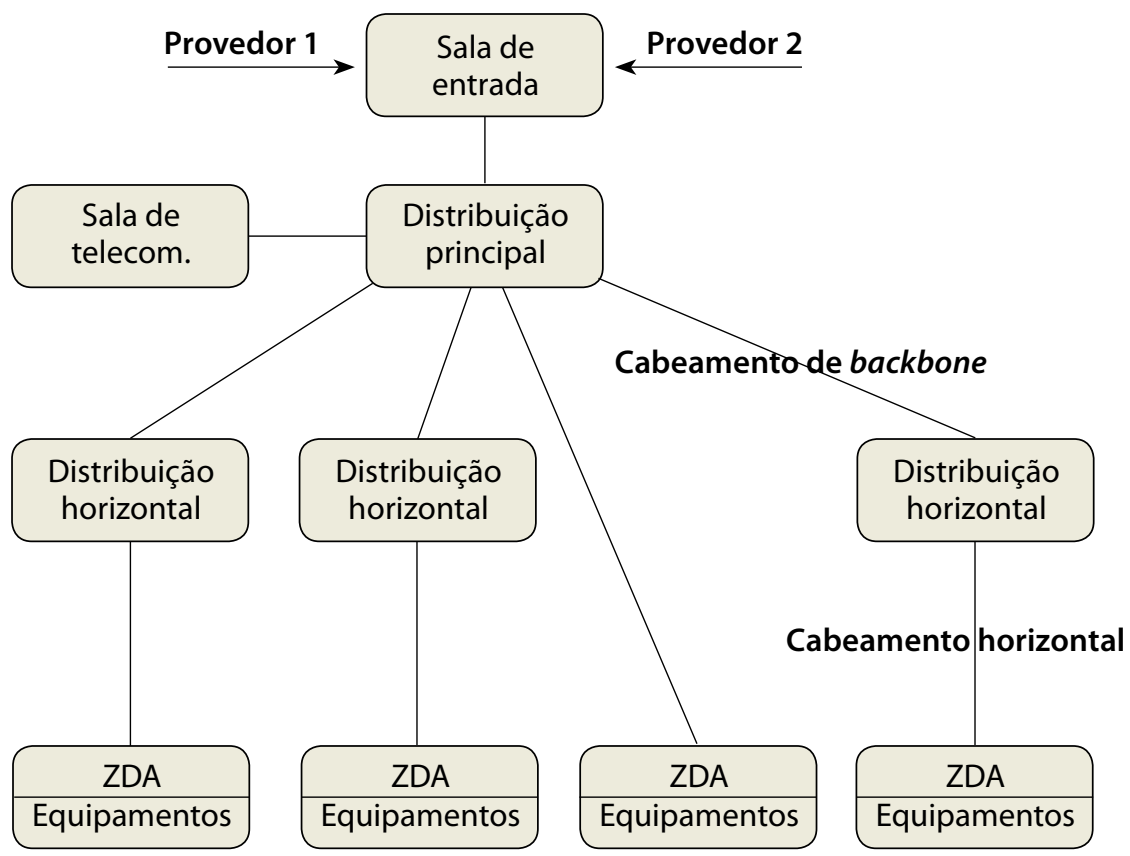


pode começar bem pequeno, com um único módulo de equipamentos, mas pode crescer sem perder sua organização.

As características de atualização tecnológica, modularidade e padronização aparecem também na infraestrutura de energia, refrigeração e outros aspectos ambientais do data center, como se verá a seguir.

\section{ASPECTOS AMBIENTAIS DE UM DATA CENTER}

O desafio dos novos projetos de data center é conseguir maior eficiência dos diversos elementos construtivos e de instalação, o que se traduz em menor consumo. Entre os vários elementos a serem considerados, pode-se citar:

- energia para alimentação dos equipamentos de rede e servidores;

- ar condicionado;

- geração e manutenção da energia;

- elementos de detecção e combate a incêndio que não agridam a natureza e que não coloquem em risco a continuidade das atividades;

- segurança e controle de acesso uma vez que os dados armazenados podem ser de extrema importância para quem os armazena.

A energia para o IDC (internet data center) é o elemento sensível, uma vez que é fundamental não só para a alimentação dos servidores e equipamentos de rede como também para o ar-condicionado, que é considerado o vilão do consumo de energia elétrica.

Quando se projeta a distribuição de energia, deve-se ter em mente os seguintes critérios de projeto:

- queda de tensão;

- fator de agrupamento;

- temperatura;

- proteção.

Vale lembrar que toda a distribuição, por meio de cabos, também é uma resistência que consome energia e a dissipa em forma de calor. O custo da energia é cada vez mais um componente importante nos custos operacionais na construção de um IDC. Nesse sentido, todos os esforços possíveis devem ser feitos para conter gastos desnecessários.

Deve ser observado que as perdas por calor geradas em um cabo caminham lado a lado com uma redução na tensão disponível na extremidade junto à carga. Desse modo, é de bom senso supor que se devam adotar projetos de distribuição que visem reduzir, na prática, as perdas de energia.

Teoricamente, seria possível reduzir a perda de energia a valores insignificantes, aumentando-se a seção do condutor. No entanto, como isso significa aumentar o custo do cabo, tende-se a anular a economia conseguida pela melhoria da eficiência na distribuição, sendo necessário encontrar-se então um compromisso entre essas duas variáveis.

A melhor ocasião para incorporar uma distribuição de alta eficiência é na etapa de projeto, quando custos adicionais são marginais. É fácil compreender que, após a instalação, é muito mais difícil e caro incorporar melhorias a um circuito.

O problema central é o de identificar uma seção de condutor que reduza o custo da energia desperdiçada, sem incorrer em custos iniciais excessivos de compra e instalação de um cabo. Cabe ao projetista, durante a fase de planejamento, estudar a melhor forma para que, no tempo, um correto dimensionamento da distribuição do sistema elétrico se torne eficiente e retorne em benefícios para a instalação.

Outro ponto que deve ser levado em consideração e que também afeta o cálculo dos condutores elétricos é a utilização de cabos com capa externa do tipo livre de halogênios e baixa emissão de fumaça, mantendo, dessa forma, maior tempo para que os usuários possam deixar o local de forma adequada no caso de um princípio de incêndio.

Também deve ser considerada, no projeto, a maneira de se instalar o cabo, ou seja, por meio de piso elevado com eletrocalhas, tubulações metálicas rígidas, flexíveis, canaletas de parede, espaços de construção, eletrocalhas 
entre forro e teto, por meio de leitos para cabos, o que também impacta no cálculo eficiente e é fator determinante para a construção de um data center adequado e que permita a fácil modificação no layout no decorrer do tempo.

Não se pode esquecer, nesse cenário elétrico, os seguintes pontos:

1. Uma proteção eficiente por meios de seccionadores do tipo disjuntores de boa qualidade ou fusíveis, conforme o caso.

2. Um projeto levando em conta a seletividade dos quadros de forma a não desligar circuitos que não fazem parte da falha e prejudicam o funcionamento do data center.

Um sistema bem dimensionado leva em conta o cálculo correto dos cabos, bem como a proteção para evitar que trabalhem em condições não permitidas ou que causem princípio de incêndio ou aquecimento (sobrecarga), com consequente parada do data center, o que representa altos custos e falta de confiabilidade na visão dos clientes.

Como exemplo, o gráfico da Figura 5 mostra a curva do cabo e do elemento de proteção.

3. Um sistema de proteção do tipo DPS (dispositivo de proteção contra surtos de origem atmosférica).

O sistema de DPS protege os equipamentos sensíveis, como roteadores, switches, modems e servidores, contra surtos de origem atmosférica que danificam esses equipamentos forçando a uma parada não desejada. A Figura 7 mostra um caso de surto atmosférico que danificou um sistema eletrônico.

A instalação do DPS, quando bem projetado, protege os equipamentos sensíveis e pode ser instalado, conforme Figura 6, nos circuitos de distribuição monofásico, bifásico ou trifásico.

4. Um bom sistema de força ininterrupta (UPS) - no-break.

O UPS é um equipamento obrigatório no projeto de qualquer IDC, desde os mais sofisticados até os mais simples. Mantém os servidores e equipamentos de rede energizados até que o gerador ou uma fonte alternativa de energia alimente o sistema, ou para que os administradores de rede possam ter tempo hábil para desligar os equipamentos e evitar que os arquivos sejam corrompidos ou que o sistema seja danificado pela queda abrup-

\section{FIGURA 5}

\section{CURVA DO CABO X CURVA DA PROTEÇÃO - INTEGRAL DE JOULE}

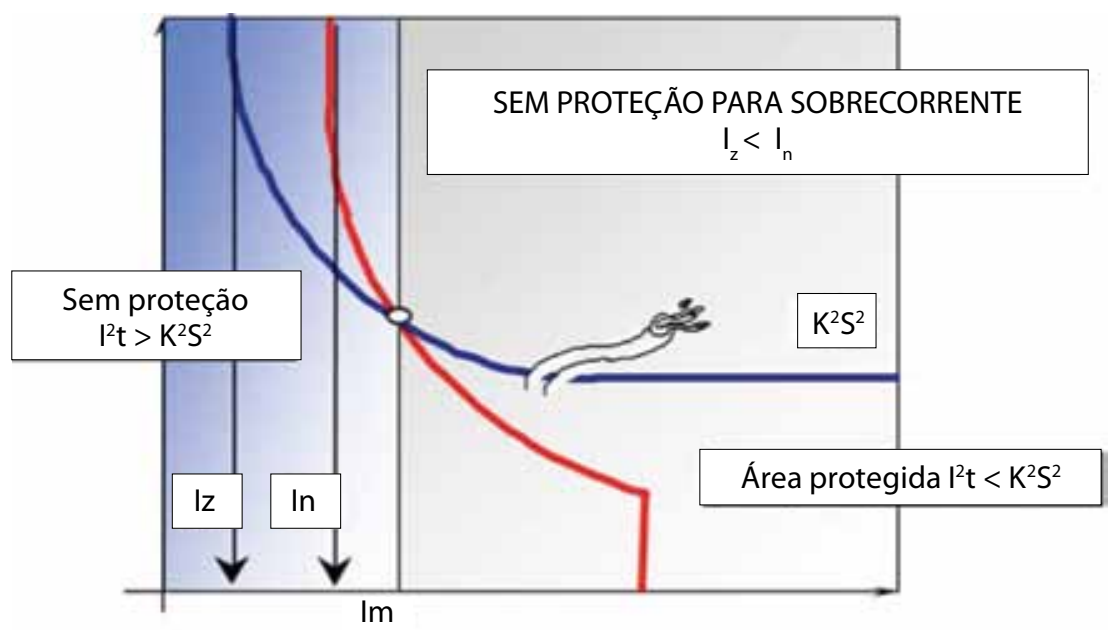




\section{LIGAÇÃO DE PROTETORES DE SURTO}

\section{Instalação do DPS antirraio}

Instalação com proteção no modo comum:
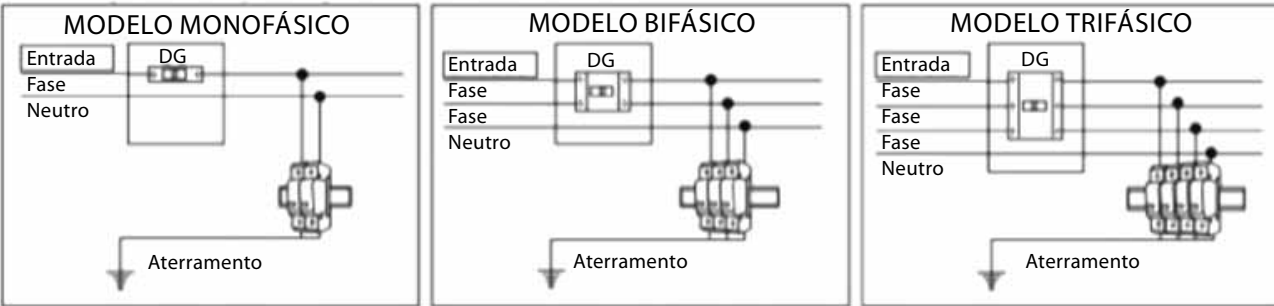

Instalação com proteção no modo comum e transverso:
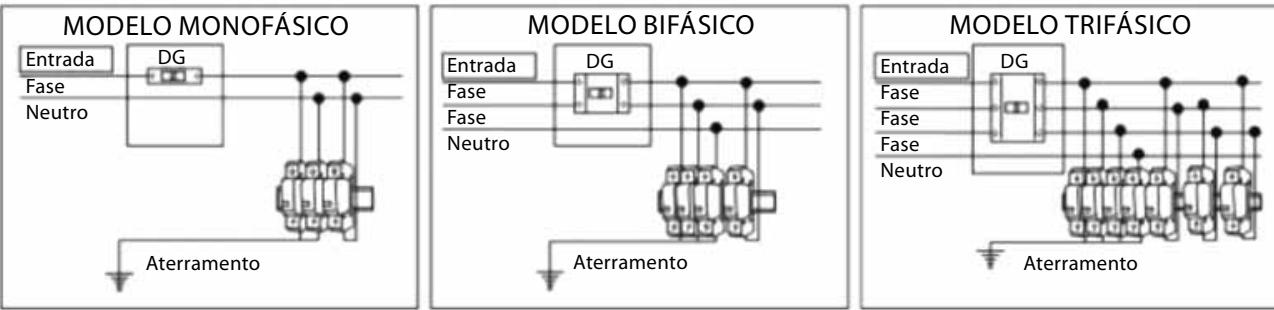

L

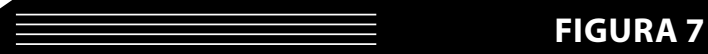

EQUIPAMENTO DANIFICADO POR DESCARGA ATMOSFÉRICA

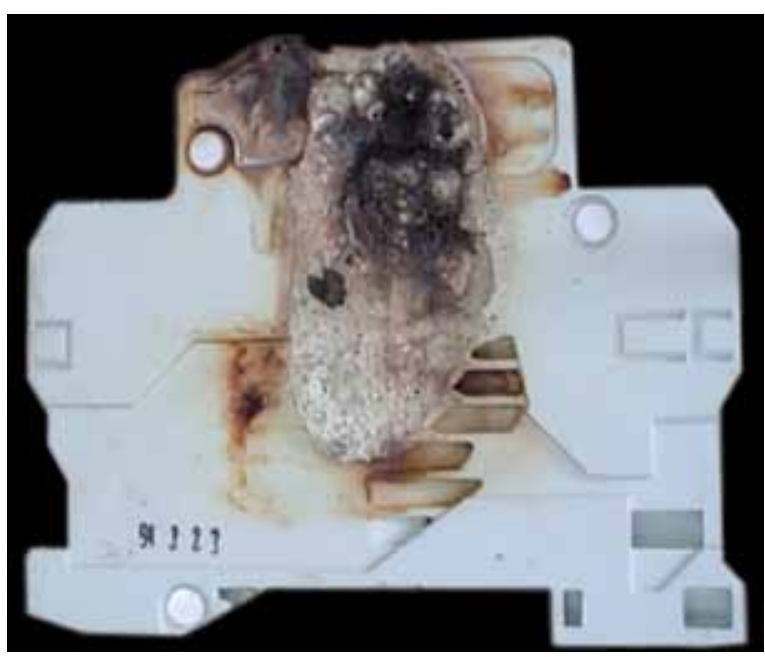


ta de energia, o que é comum no Brasil em função da falta de qualidade da distribuição de energia, como temos visto nos noticiários nos últimos tempos.

Existem diversos modelos de UPS no mercado, sendo o mais comum o de bateria de chumbo ácido, mas já existe a novidade apresentada no mercado japonês de um sistema com bateria de lítio e carga por meio de luz solar (Figura 8).

5. Um sistema de geração de energia a gás ou óleo combustível com baixa emissão de poluentes.

Os geradores são, assim como o UPS, equipamentos obrigatórios, principalmente nos grandes IDCs.

O maior objetivo hoje é minimizar o impacto desses equipamentos no meio ambiente, uma vez que são motores baseados em óleo diesel que, mesmo com os novos combustíveis dos dias de hoje, ainda têm seu fator poluente.

Qual seria a alternativa?

Alguns apostam no biogás. Outros apostariam no sistema eólico ou sistema solar.
Tais sistemas ainda estão longe de ser eficientes, além do custo, que inviabiliza a adoção desse tipo de tecnologia neste momento.

A Figura 9 apresenta uma alternativa com a utilização de biogás, menos agressivo ao meio ambiente.

Os grupos geradores a biogás - lean-burn - são destinados às aplicações de geração e/ ou cogeração, e utilizam o biogás derivado de aterros sanitários, biodigestores e gases de mina. O biogás fornecido é transformado em energia, possibilitando um ganho financeiro a partir de uma fonte de energia renovável.

A alternativa é o uso de sistemas eólicos, como mostra a Figura 10.

6. Um sistema de para-raios eficiente.

O SPDA minimiza o impacto de descargas diretas, o que deve ser complementado com o uso de DPS. Não se deve esquecer de efetuar a devida equalização dos potenciais interligando todas as massas metálicas, inclusive o sistema de aterramento do para-raios, elétrica e telemática, em um único ponto ou em uma caixa de equalização de potenciais (LEP).

\section{SISTEMA DE UPS FABRICADO NO JAPÃO COM BATERIA DE LÍTIO \\ E RECARGA POR ENERGIA SOLAR}

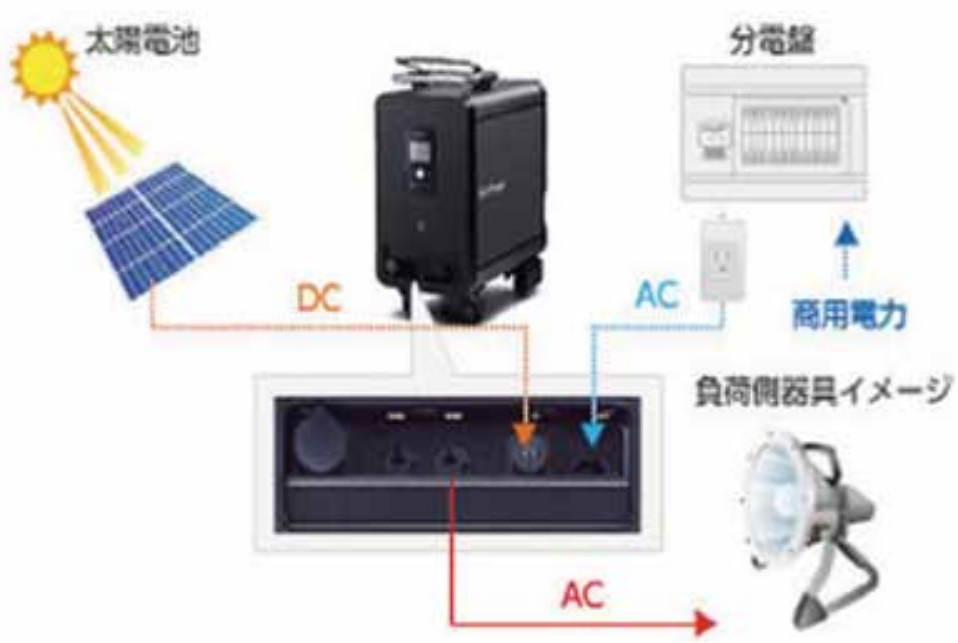




\section{FIGURA 9}

\section{GERAÇÃO DE ENERGIA}

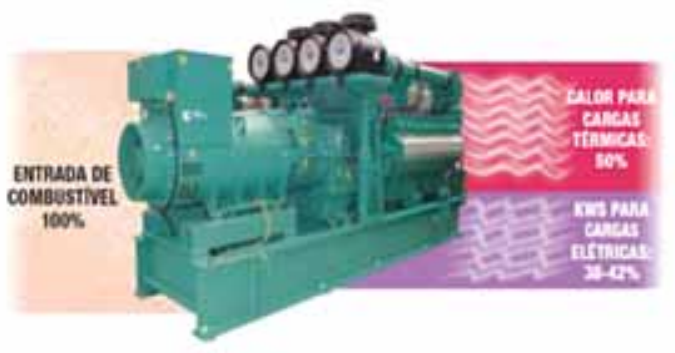

Cogeração - para eficiência energética

O sistema de cogeração normalmente consiste em uma máquina motriz que gira um alternador para produzir eletricidade e em um sistema de recuperação para captar calor dos gases de escape e da água de resfriamento da máquina motriz. Essa máquina motriz pode ser um motor lean-burn a gás natural ou uma turbina a gás. Mais de $90 \%$ da energia do combustível original pode ser aproveitada. A economia total de energia pode chegar a $35 \%$ ou mais.

\begin{tabular}{|c|c|c|c|c|c|c|c|c|}
\hline \multicolumn{9}{|l|}{ Biogás } \\
\hline \multirow[t]{2}{*}{ Modelo } & $\begin{array}{c}\text { Pot. elétrica } \\
\text { contínua }\end{array}$ & Motor & \multicolumn{3}{|c|}{ Versão aberta open set } & $\begin{array}{l}\text { Eficiência } \\
\text { elétrica }\end{array}$ & Emissão NOx & $\begin{array}{l}\text { Rot. do } \\
\text { motor }\end{array}$ \\
\hline & $\mathrm{kW}^{* *}$ & Tipo & $\begin{array}{c}\text { Compr. } \\
(\mathrm{m})\end{array}$ & $\begin{array}{c}\text { Larg. } \\
(\mathrm{m})\end{array}$ & $\begin{array}{l}\text { Peso } \\
(t)\end{array}$ & $(\%)^{*}$ & (g/hp-h) & rpm \\
\hline C1750N6C LBTU & 1570 & QSV91G & 7,4 & 2,1 & 21,1 & 36,3 а 37,1 & 1,2 & 1500 \\
\hline C2000N6C LBTU & 2000 & QSV91G & 7,1 & 2,2 & 20,7 & 37,1 & 0,5 & 1514 \\
\hline
\end{tabular}

\section{FIGURA 10}

\section{SISTEMA DE GERAÇÃO DE ENERGIA LIMPA - EÓLICO}

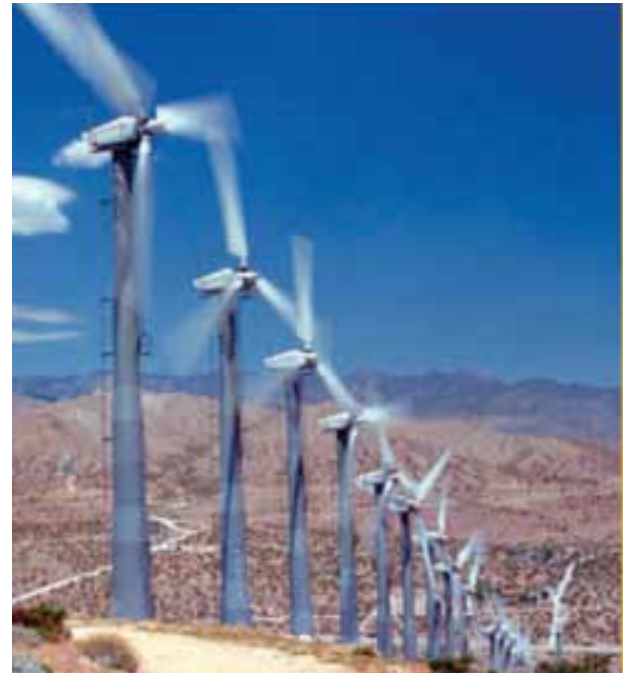

\section{SISTEMA DE SPDA - UTILIZAÇÃO DA FERRAGEM ESTRUTURAL}

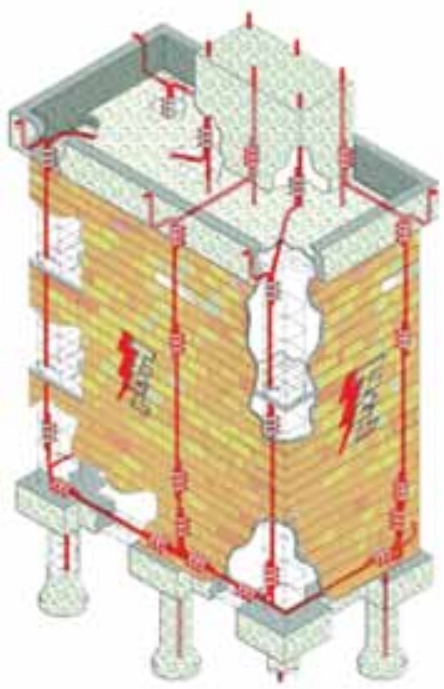


A Figura 11, obtida do catálogo de um fabricante, ilustra o sistema SPDA.

\section{Ar-condicionado.}

A instalação de sistemas de ar-condicionado, vilões no consumo de energia, deve ser projetada de forma adequada com a utilização de corredores quente e frio ou mesmo do confinamento das áreas quentes, minimizando a área para resfriamento, o que impacta em menores custos de energia elétrica e espaço.

O segredo para o projeto de um sistema de refrigeração eficiente é a separação do ar quente e do ar frio, o que não ocorre em um sistema mal projetado, como mostra a Figura 12.

A Figura 13 mostra uma alternativa mais eficiente, com corredores quentes e frios. Todo o ar passa do corredor frio para o quente através dos equipamentos a serem resfriados.

8. Sistema de detecção e combate a incêndio.

Todo o sistema de processamento de da-

\section{FIGURA 12}

\section{SISTEMA TRADICIONAL: O AR QUENTE SE MISTURA COM O AR FRIO}

No resfriamento tradicional o espaço todo é inundado e mistura o ar quente e o frio

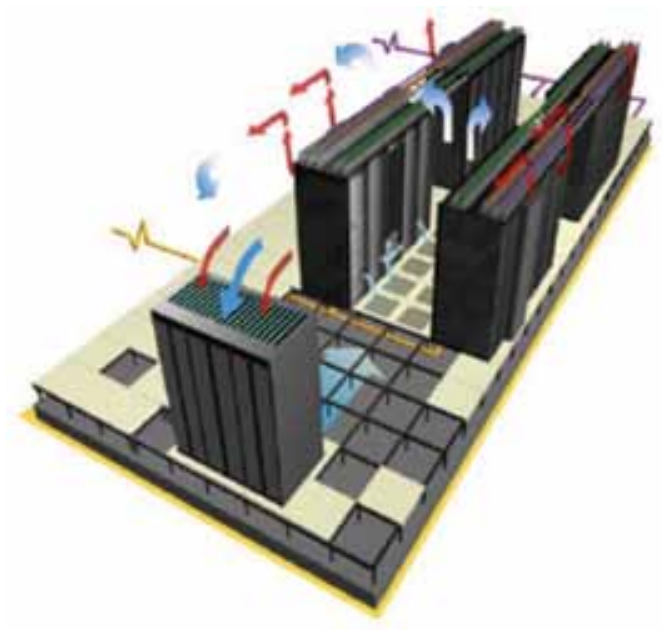

dos deve também ter um sistema eficiente de detecção e combate a incêndio.

O combate deve ser tal que não agrida os equipamentos de rede e que possibilite o retorno ao funcionamento o mais breve possível. Nesse cenário foram desenvolvidos agentes extintores de incêndio como o FM 200 e Novec 1230 (nomes comerciais) que garantem a extinção sem prejudicar os equipamentos envolvidos, como acontecia anteriormente com extintores de pó ou água conforme o caso.

A Figura 14 ilustra o sistema FM 200 com cilindros em linha.

$\mathrm{Na}$ extinção de incêndio tem-se uma grande diversidade de sensores e sistemas que podem ser extremamente sensíveis, como o caso da detecção por aspiração ou sensores de fumaça ou temperatura.

A Figura 15 apresenta um sistema comum para detecção de incêndio utilizando sistemas de distribuição serial (laço), com cada dispositivo endereçado de forma a identificar corretamente a localização do princípio de incêndio.
FIGURA 13

\section{REFRIGERAÇÃO COM CORREDOR QUENTE E FRIO}

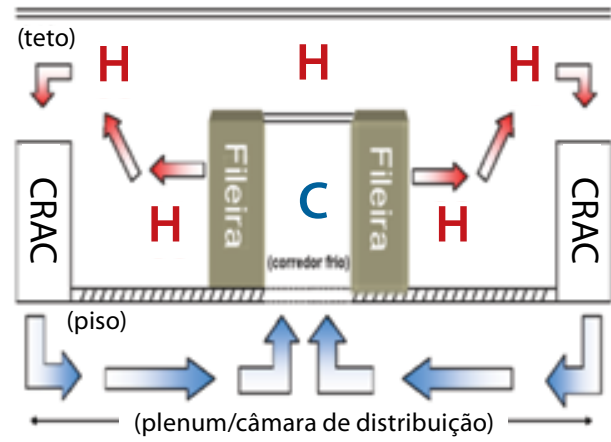




\section{FIGURA 14}

\section{LINHA DE CILINDROS PARA EXTINÇÃO DE INCÊNDIO UTILIZANDO FM-200}

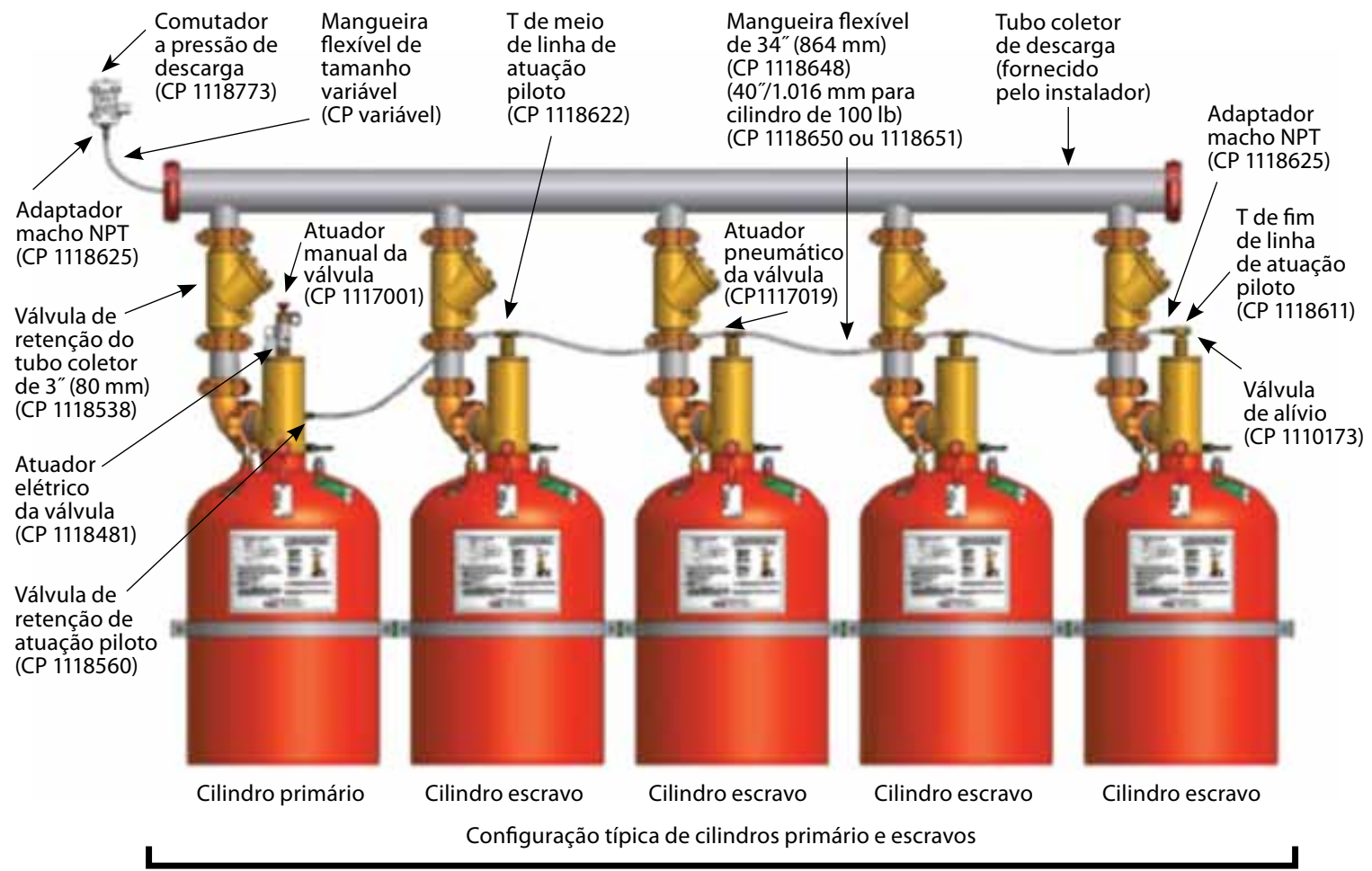

\section{FIGURA 15}

\section{SISTEMA DE DETECÇÃO DE INCÊNDIO}

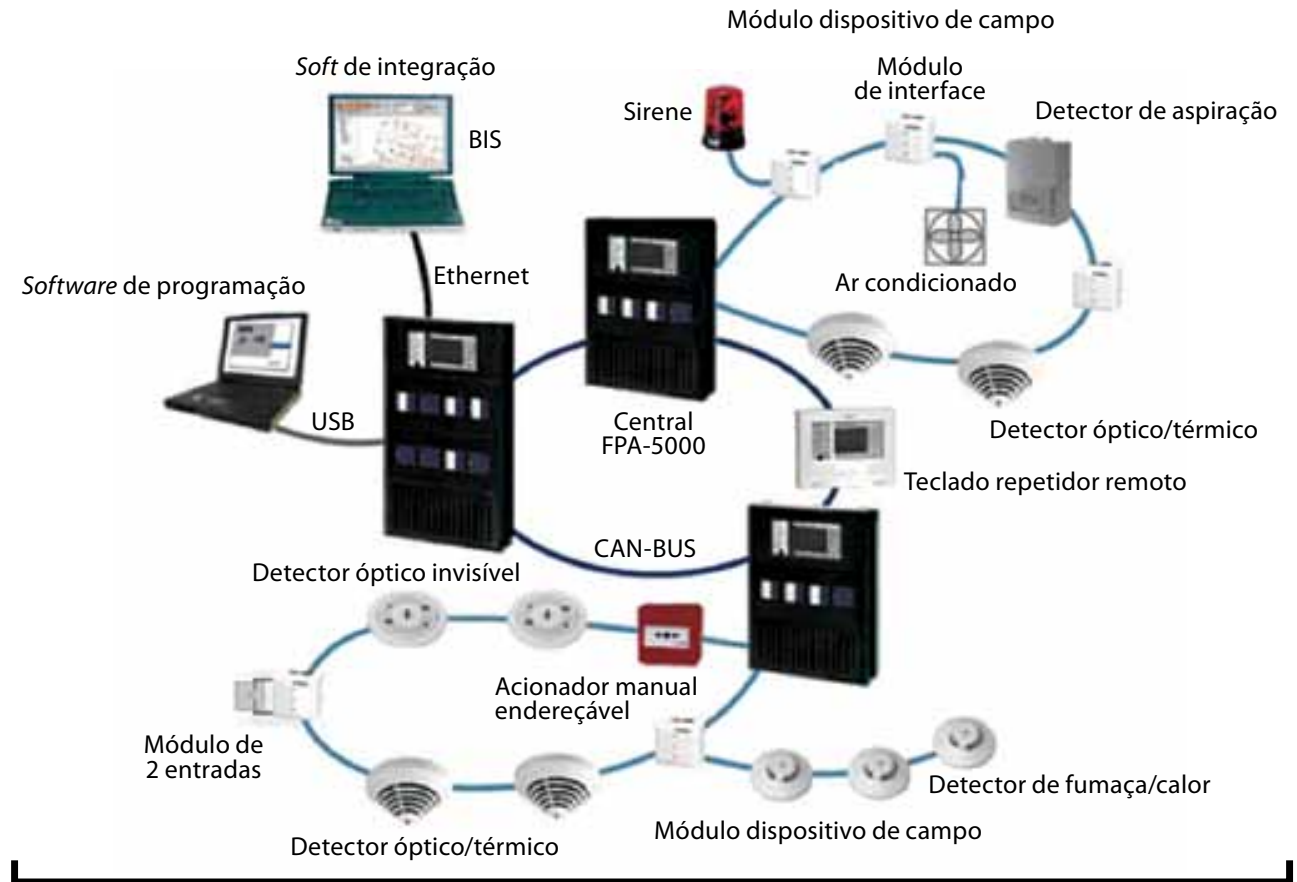




\section{MONITORAÇÃO E IDENTIFICAÇÃO BIOMÉTRICA}

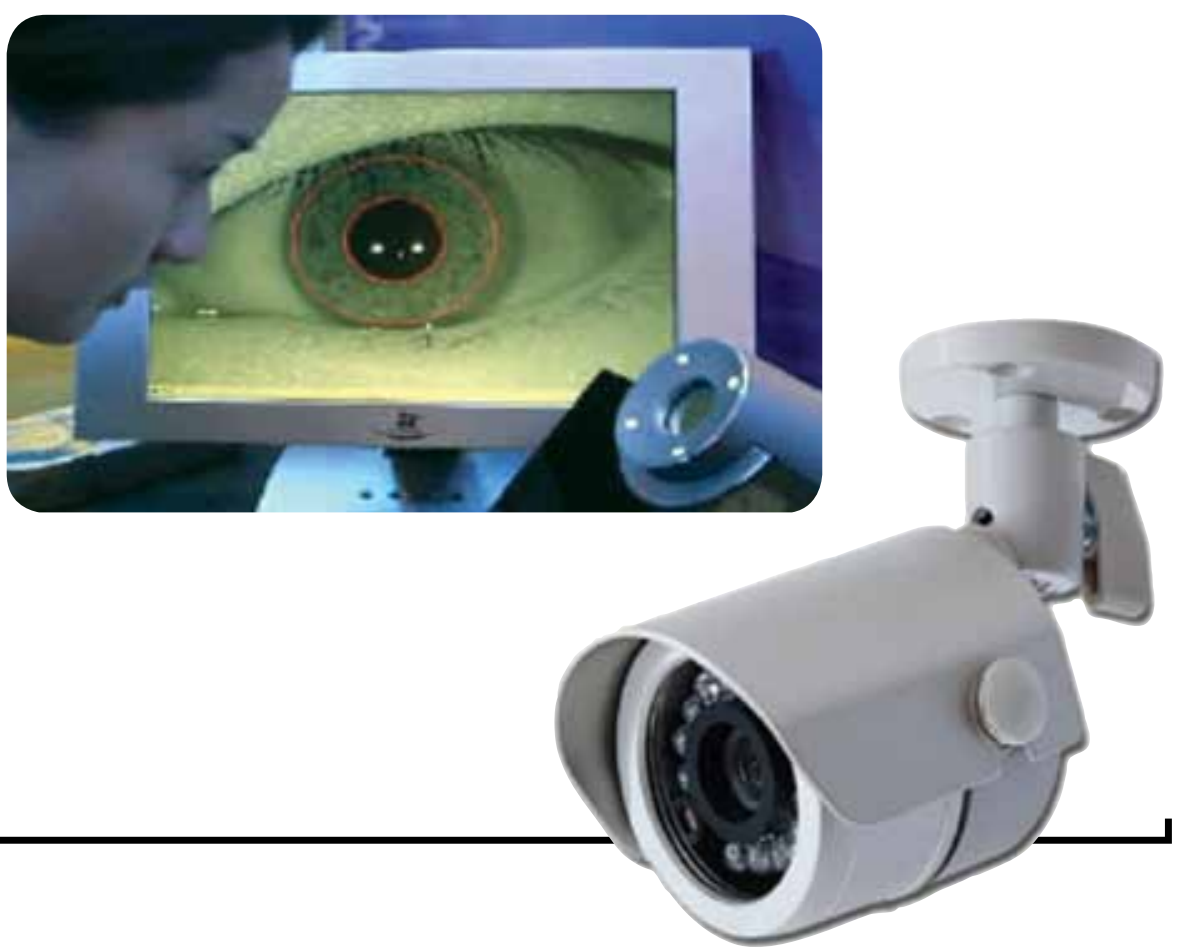

Finalmente, entre os itens que se consideram importantes no projeto de data center, não se pode esquecer o controle de acesso a esse ambiente que é tão importante e vital.

Existem hoje diversos sistemas de autenticação, sendo os mais sofisticados os biométricos. Sistemas sofisticados de identificação pela íris, palma da mão, reconhecimento da face e até pelo odor podem ser encontrados. A Figura 16 apresenta uma ilustração desses sistemas.

Todos esses sistemas podem e devem ser monitorados por softwares de gerenciamento da infraestrutura baseado em rede de dados por meio de protocolos tipo SNMP ou gerenciamentos baseados na Web. Sem um sistema efetivo de gerenciamento, as falhas demoram a ser detectadas e o são, muitas vezes, quando seus efeitos já se tornaram irreversíveis.

A Figura 17 ilustra a operação do sistema de gerenciamento de ambiente.

Esses sistemas de gerenciamento são inte- grados a ponto de ativar ou desativar servidores em momentos críticos, acionar um sistema de combate a incêndio, geração de energia, UPS, detectar intrusão e avisar os gestores por meio de e-mail, SMS, ou outras formas sobre os eventos ocorridos no data center.

\section{COMPUTAÇÃO EM NUVEM}

As pessoas por vezes têm a impressão de que, com a disseminação da computação em nuvem, os data centers tendem a diminuir em tamanho e em importância. É pouco provável que tal ocorra.

A computação em nuvem significa que a capacidade de processamento pode ser alocada de forma dinâmica, independente de localização física, mas é exatamente nos data centers que essa capacidade computacional reside. 


\section{FIGURA 17}

\section{SISTEMA DE GERENCIAMENTO DA INFRAESTRUTURA}

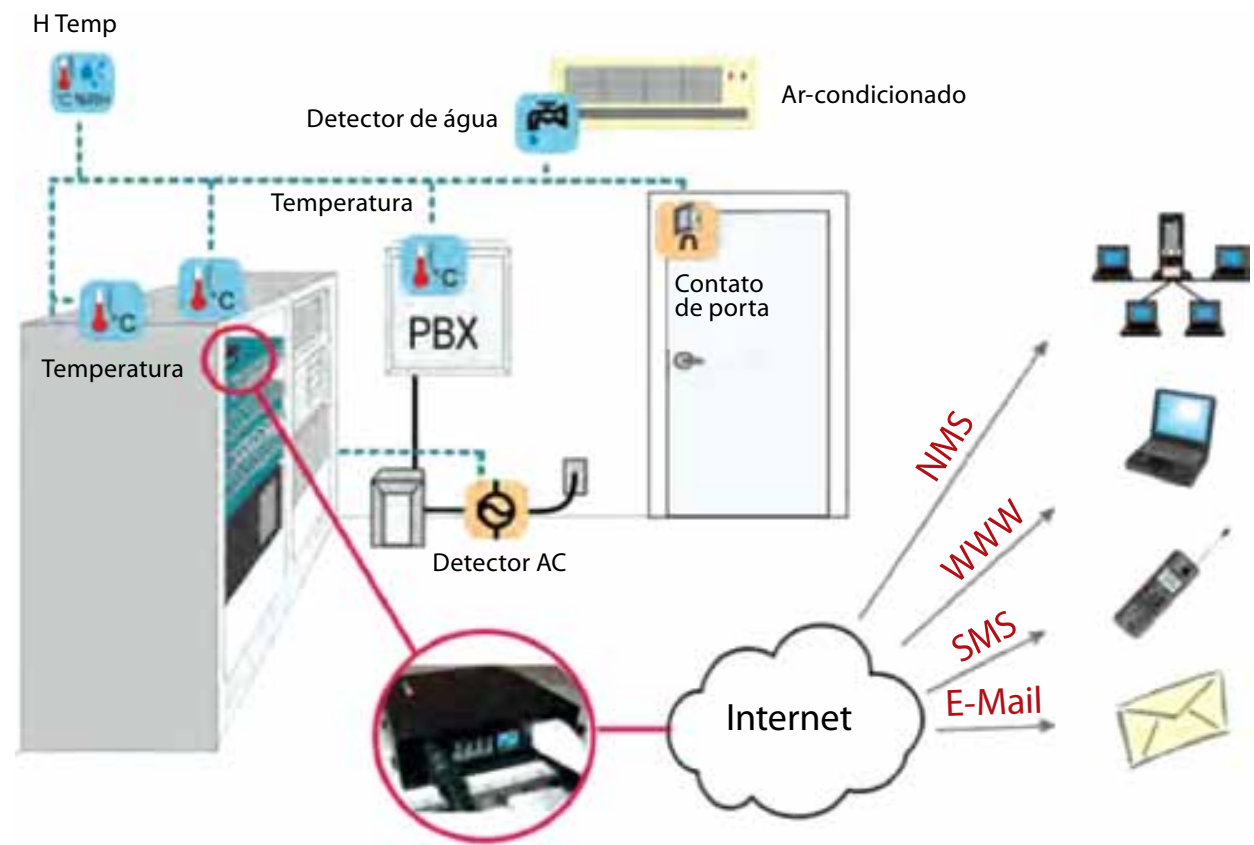

Em outros tempos, uma aplicação executava em uma máquina com específicas características físicas e de sistema. De uma forma ou de outra acabavam por aparecer dependências entre a aplicação e o seu ambiente, de modo que ficava difícil encontrar um ambiente equivalente quando se queria migrar a aplicação de uma máquina para outra.

Com a virtualização tudo mudou. As características físicas de um computador, bem como seu ambiente operacional, passam a ser virtuais e também podem ser mudados de um equipamento físico para outro.

É óbvio que isso aumenta muito a importância da normalização. Ao invés de se ter um módulo de processamento físico, compatível com algumas aplicações, mas não com outras, ele passa a ser virtual e compatível com um número muito maior de aplicações de potenciais clientes. 